\title{
The effect of synthetic pyrethroids on the attachment and host-feeding behaviour in Dermacentor reticulatus females (Ixodida: Amblyommidae)
}

\author{
Alicja Buczek*, Patrycja Lachowska-Kotowska and Katarzyna Bartosik
}

\begin{abstract}
Background: The high competence of D. reticulatus in transmission of tick-borne pathogens prompts investigations of the effect of chemicals used as repellents and acaricides on the behaviour of the tick on the host. Therefore, this paper presents the effect of permethrin and deltamethrin on the attachment and feeding in this tick species.

Findings: Attachment to rabbit skin of $D$. reticulatus females sprayed with pyrethroids and the effect of different doses thereof on feeding were assessed at a temperature of $20 \pm 3{ }^{\circ} \mathrm{C}$ and $50 \%$ humidity.

The dynamics of attachment of $D$. reticulatus females varied in a dose-dependent manner after the application of both pyrethroids. Within the first $0.5 \mathrm{~h}$ of the experiments, there was an over six-fold and over twelve-fold increase in the number of females attached to host skin after application of permethrin concentrations of 0.3906-0.7812 $\mu \mathrm{g}$ and $1.5625-3.1250 \mu \mathrm{g} / 1$ specimen, respectively. In the case of deltamethrin, females treated with the dose of $0.0390 \mu \mathrm{g}$ of the compound were able to attach to host skin only 4 hours after the infestation.

The toxic activity of both pyrethroids increased the duration of the feeding period and decreased the body weight of engorged females and the feeding efficiency index.

Conclusions: The accelerated attachment of $D$. reticulatus females caused by sublethal permethrin doses and delayed or inhibited attachment caused by deltamethrin suggest a necessity of careful selection of the type and dose of pyrethroids to protect hosts from tick attacks.
\end{abstract}

Keywords: Dermacentor reticulatus, Permethrin, Deltamethrin, Attachment behaviour, Host-feeding behaviour

\section{Background}

The most effective method for reduction of the threat posed by ticks to human [1] and animal health is to use repellents and acaricides. However, chemicals can produce adverse effects, e.g. behavioural changes and toxicoses in animals $[2,3]$ as well as disturbances in the function of various systems in humans [4]. Moreover, long-term use and/or application of inadequate doses of the compounds may result in development of resistance of ticks to these chemicals $[5,6]$.

Among the chemicals applied in tick control, synthetic pyrethroids are widely used as repellents for protection of humans [7-9] and animals [10-12] and as tick control agents [13-18].

In order to achieve higher effectiveness of pyrethroids in tick control and to reduce the disease-related effects of tick parasitism, detailed knowledge about their effect on different species of ticks in the parasitic phase of their life cycle is particularly important. Therefore, this paper describes for the first time the effect of sublethal doses of permethrin and deltamethrin on the attachment and feeding behaviour of females of the meadow tick Dermacentor reticulatus (Fabricius), a common species in large areas of the Palearctic.

\footnotetext{
* Correspondence: alicja.buczek@umlub.pl

Department of Biology and Parasitology, Medical University,

Radziwiłłowska11 St., 20-080 Lublin, Poland
} 


\section{Methods}

\section{Acaricides}

Hungry females were treated with formulations of two pyrethroids: permethrin (Coopex 25WP) and deltamethrin (K-Othrine 2,5 flow). Each hungry female received a single application of $10 \mu \mathrm{l}$ of one of the tested pyrethroid solutions (Table 1).

\section{Ticks}

The $D$. reticulatus adults examined in this experiment were collected in the Lublin macroregion $\left(51^{\circ} 15^{\prime} \mathrm{N}, 22^{\circ}\right.$ $\left.36^{\prime} \mathrm{E}\right)$ between September and October. Before acaricide tests, adult $D$. reticulatus ticks were kept in glass rearing chambers at room temperature of ca. $20{ }^{\circ} \mathrm{C}$ and $90 \%$ humidity. Only morphologically intact ticks were used.

\section{Acaricide testing procedure}

Each female was weighed with an accuracy of $0.0001 \mathrm{~g}$ using an analytical digital balance; next, the pyrethroid solutions were applied with a micropipette onto its dorsal side. The next day, the females and untreated males were placed on rabbits' skin.

Each pyrethroid solution was tested on 3 New Zealand albino rabbits, each of which was infested by 10 females and 5 males. The course of tick attachment and feeding on the host was observed at a temperature of $20 \pm 3{ }^{\circ} \mathrm{C}$ and $50 \%$ humidity.

The course of attachment to the host skin in each experimental group of $D$. reticulatus females and in the control group was assessed at 0.5 -h intervals for 7 h, i.e. until the attachment of the last female. After the ticks began feeding, the experimental animals were viewed once a day at the same time and detached females were collected. Next, the females were weighed using an analytical balance and transferred to rearing chambers.

The experiments in the control group were conducted analogously to the pyrethroid tests, but the females were treated with $10 \mu \mathrm{l}$ of distilled water instead of the solution of the chemical substance.

In all the experimental groups, attachment of $D$. reticulatus females to the host and the course of the parasitic phase were assessed based on several parameters (Tables 2 , 3 and 4).

Table 1 Quantity of active substance in $10 \mu$ l of a permethrin and deltamethrin solutions applied as a single dose (in $\mu \mathrm{g}$ )

\begin{tabular}{lcc}
\hline $\begin{array}{l}\text { Concentration of the solution } \\
(\%)\end{array}$ & $\begin{array}{l}\text { Permethrin } \\
(\mu \mathrm{g})\end{array}$ & $\begin{array}{l}\text { Deltamethrin } \\
(\mu \mathrm{g})\end{array}$ \\
\hline 0.0156 & 0.3906 & 0.0390 \\
0.0312 & 0.7812 & 0.0781 \\
0.0625 & 1.5625 & 0.1562 \\
0.1250 & 3.1250 & 0.3125 \\
0.2500 & 6.2500 & 0.6250 \\
\hline
\end{tabular}

\section{Statistical analysis}

The U Mann - Whitney test was employed to check whether there were significant differences in the values of the parameters between the control and experimental groups. With the use of the $\mathrm{H}$ Kruskal-Wallis test, we verified the hypothesis of equality of the parameters for the different concentrations of the acaricides applied. In both tests, a significant statistical difference was established at $\mathrm{p} \leq 0.05$ and a highly significant difference at $\mathrm{p} \leq 0.01$.

\section{Ethical approval}

The study was performed with the full approval of Commission for Animal Experiments.

\section{Findings}

Permethrin and deltamethrin applied at sublethal doses altered the host-feeding behaviour of $D$. reticulatus ticks. Unengorged females treated with permethrin attached themselves to the host earlier than the females from the control group (Table 2). Within the first $0.5 \mathrm{~h}$ of the experiment, an over six-fold greater number of females treated with 0.390625 to $0.78125 \mu \mathrm{g}$ of permethrin were found attached to rabbits' skin than in the control group. Even greater differences between the tested and control groups were observed at the application of the higher concentrations of permethrin, which was confirmed by the values of the attachment index ratio (Fig. 1). Depending on the dose, deltamethrin delayed or completely prevented the attachment of tick females to rabbits' skin (Table 2). Unengorged, deltamethrin-treated D. reticulatus females attached themselves to the host and started feeding 4 hours after host infestation only when the $0.0390 \mu \mathrm{g}$ dose was applied (Table 2). The attachment rate index at this point of the experiment was only 1.13 (Fig. 1).

The treatment of $D$. reticulatus females with both pyrethroids resulted in prolongation of the feeding period, but in comparison with the control group, these differences were not statistically significant (Table 3 and 4). After a longer feeding period, females treated with the $0.3906 \mu \mathrm{g}$ permethrin dose exhibited a statistically significantly decrease in body weight and their feeding efficiency decreased compared with the control (Table 3). The feeding efficiency declined, reaching the threshold of statistically significant differences in the female group treated with the different concentrations of permethrin (Table 3).

After the application of the tested deltamethrin dose, the values of the feeding parameters decreased, but did not exhibit statistically significant differences, compared with the control (Table 4).

\section{Discussion}

Our research, carried out on unengorged D. reticulatus specimens for the first time, has shown that sublethal doses of permethrin increase the activity of hungry 
Table 2 Attachment of D. reticulatus females (\%) under the influence of pyrethroids studied and in control group at temperature $20 \pm 3^{\circ} \mathrm{C}$ and $50 \pm 3^{\circ} \% \mathrm{RH}$

\begin{tabular}{|c|c|c|c|c|c|c|c|c|c|c|c|c|c|c|c|}
\hline \multirow[t]{2}{*}{ Pyrethroid } & \multirow{2}{*}{$\begin{array}{l}\text { Concentration } \\
(\%)\end{array}$} & \multicolumn{14}{|c|}{ Time (h) } \\
\hline & & 0.5 & 1 & 1.5 & 2 & 2.5 & 3 & 3.5 & 4 & 4.5 & 5 & 5.5 & 6 & 6.5 & 7 \\
\hline \multirow[t]{4}{*}{ Permethrin } & 0.015625 & 25 & 50 & 50 & 50 & 50 & 50 & 100 & 100 & 100 & 100 & 100 & 100 & 100 & 100 \\
\hline & 0.03125 & 25 & 25 & 25 & 25 & 50 & 50 & 75 & 75 & 100 & 100 & 100 & 100 & 100 & 100 \\
\hline & 0.0625 & 67 & 100 & 100 & 100 & 100 & 100 & 100 & 100 & 100 & 100 & 100 & 100 & 100 & 100 \\
\hline & 0.125 & 50 & 50 & 50 & 100 & 100 & 100 & 100 & 100 & 100 & 100 & 100 & 100 & 100 & 100 \\
\hline Deltamethrin & 0.015625 & 0 & 0 & 0 & 0 & 0 & 0 & 0 & 100 & 100 & 100 & 100 & 100 & 100 & 100 \\
\hline Control & & 4.0 & 24.0 & 36.0 & 48.0 & 56.0 & 68.0 & 80.0 & 88.0 & 92.0 & 96.0 & 96.0 & 96.0 & 96.0 & 100.0 \\
\hline
\end{tabular}

females of this species, which results in higher dynamics of attachment to host skin. This change in tick behaviour induced by application of permethrin may be associated with its toxic effect on synganglion cells in ticks, which has been documented by other authors [19-21].

Morphological changes and, consequently, impaired secretion of neurotransmitters can cause disturbances in conduction of nerve impulses not only in the synganglion cells but also in other organs controlled by the nervous system [22, 23]. The effects of the toxic effects of permethrin include morphophysiological changes in the reproductive organs, [21] which reduce the reproductive performance in tick females $[15,16]$, and changes in tick salivary glands $[20,24,25]$ resulting in impairment of their secretory and osmoregulatory function.

The differences in the behaviour of hungry $D$. reticulatus females on the host induced by permethrin and deltamethrin are related to the different toxicity of both these substances and the different mechanism of action of these pyrethroids. In our previous studies, we reported that deltamethrin applied to hungry and engorged $D$. reticulatus females produced stronger toxic effects than permethrin [16].

In these investigations, the toxic effect of pyrethroids on $D$. reticulatus females during the parasitic phase was manifested by changes in the analysed parameters. The

Table 3 Parameters of parasitic phase in Dermacentor reticulatus females infesting the rabbit host, after application of permethrin solutions on unfed females at temperature $20 \pm 3^{\circ} \mathrm{C}$ and $50 \pm 3^{\circ} \% \mathrm{RH}$

\begin{tabular}{|c|c|c|c|c|c|c|c|}
\hline \multirow[t]{2}{*}{ Parameter } & \multirow[t]{2}{*}{ Statistics } & \multicolumn{4}{|c|}{ Concentration of the solution (\%) } & \multirow[t]{2}{*}{ Control } & \multirow[t]{2}{*}{ H Test } \\
\hline & & 0.0156 & 0.0312 & 0.0625 & 0.1250 & & \\
\hline \multirow[t]{6}{*}{ Feeding period (days) } & Min & 12 & 7 & 9 & 9 & 6 & 6.2085 \\
\hline & Max & 17 & 17 & 13 & 13 & 16 & \\
\hline & M & 14 & 12 & 10 & 11 & 9 & \\
\hline & SD & 2.9 & 4.1 & 2.3 & 2.8 & 3,4 & $p=0.1841$ \\
\hline & U Test & 10.0 & 24.0 & 18.5 & 11.5 & $x$ & \\
\hline & $\mathrm{p}$ & 0.0605 & 0.1821 & 0.2564 & 0.2999 & $x$ & \\
\hline \multirow[t]{6}{*}{ Female engorged weight (g) } & Min & 0.1719 & 0.1294 & 0.1639 & 0.1294 & 0,1468 & 9.0366 \\
\hline & Max & 0.2772 & 0.3469 & 0.3185 & 0.3112 & 0,4637 & \\
\hline & M & 0.2346 & 0.2473 & 0.2380 & 0.2203 & 0,3329 & \\
\hline & SD & 0.0554 & 0.0898 & 0.0775 & 0.1286 & 0,0811 & $p=0.0602$ \\
\hline & U Test & 9.0 & 18.0 & 11.0 & 8.0 & $x$ & \\
\hline & $\mathrm{p}$ & 0.0495 & 0.0752 & 0.0735 & 0.1560 & $x$ & \\
\hline \multirow[t]{6}{*}{ Feeding efficiency index * $(g / 24$ h) } & Min & 0.0143 & 0.0108 & 0.0126 & 0.0100 & 0,0092 & 9.3192 \\
\hline & Max & 0.0212 & 0.0496 & 0.0354 & 0.0346 & 0,0740 & \\
\hline & M & 0.0173 & 0.0243 & 0.0246 & 0.0223 & 0,0421 & \\
\hline & SD & 0.0035 & 0.0175 & 0.0114 & 0.0174 & 0,0181 & $p=0.0536$ \\
\hline & $\cup$ Test & 7.0 & 20.0 & 12.0 & 7.0 & $x$ & \\
\hline & $\mathrm{p}$ & 0.0324 & 0.1029 & 0.0887 & 0.1266 & $x$ & \\
\hline
\end{tabular}


Table 4 Parameters of parasitic phase in Dermacentor reticulatus females infesting the rabbit host,after application of deltamethrin solutions on unfed females at temperature $20 \pm 3{ }^{\circ} \mathrm{C}$ and $50 \pm 3 \% \mathrm{RH}$

\begin{tabular}{|c|c|c|c|}
\hline \multirow[t]{2}{*}{ Parameter } & \multirow[t]{2}{*}{ Statistics } & Concentrationof the solution(\%) & Control \\
\hline & & \multicolumn{2}{|l|}{0.0156} \\
\hline \multirow[t]{6}{*}{ Feeding period (days) } & Min & 11 & 6 \\
\hline & Max & 12 & 16 \\
\hline & M & 12 & 9 \\
\hline & SD & 0.7 & 3.4 \\
\hline & UTest & 10.0 & $x$ \\
\hline & $p$ & 0.2300 & $x$ \\
\hline \multirow[t]{6}{*}{ Female engorged weight (g) } & Min & 0.2218 & 0.1468 \\
\hline & Max & 0.2497 & 0.4637 \\
\hline & M & 0.2358 & 0.3329 \\
\hline & SD & 0.0197 & 0.0811 \\
\hline & UTest & 4.0 & $x$ \\
\hline & $\mathrm{p}$ & 0.0636 & $x$ \\
\hline \multirow[t]{6}{*}{ Feeding efficiency index* (g/24 h) } & Min & 0.0202 & 0.0092 \\
\hline & Max & 0.0208 & 0.0740 \\
\hline & M & 0.0205 & 0.0421 \\
\hline & SD & 0.0005 & 0.0181 \\
\hline & UTest & 8.0 & $x$ \\
\hline & $p$ & 0.1560 & $x$ \\
\hline
\end{tabular}

*Average increase in body mass (in g) per 24 h,M - mean; SD - standard deviation, at deltamethrin concentrations $0.03125 \%$; $0.0625 \%$; $0.125 \%$; $0.25 \%$ i $0.5 \%$ no $D$. reticulatus female was able to complete feeding

reduced feeding efficiency index indicates changes in the dynamics and/or impaired secretion of saliva components, which play an important role in attachment of ticks to the host, digestion of host tissues, inhibition of host immune response, and transmission of some pathogens.
As shown in our research, changes in tick attachment and feeding induced by the use of pyrethroids may result in adverse interactions between ticks and the host and have a detrimental effect on the host. This issue, however, needs elucidation.

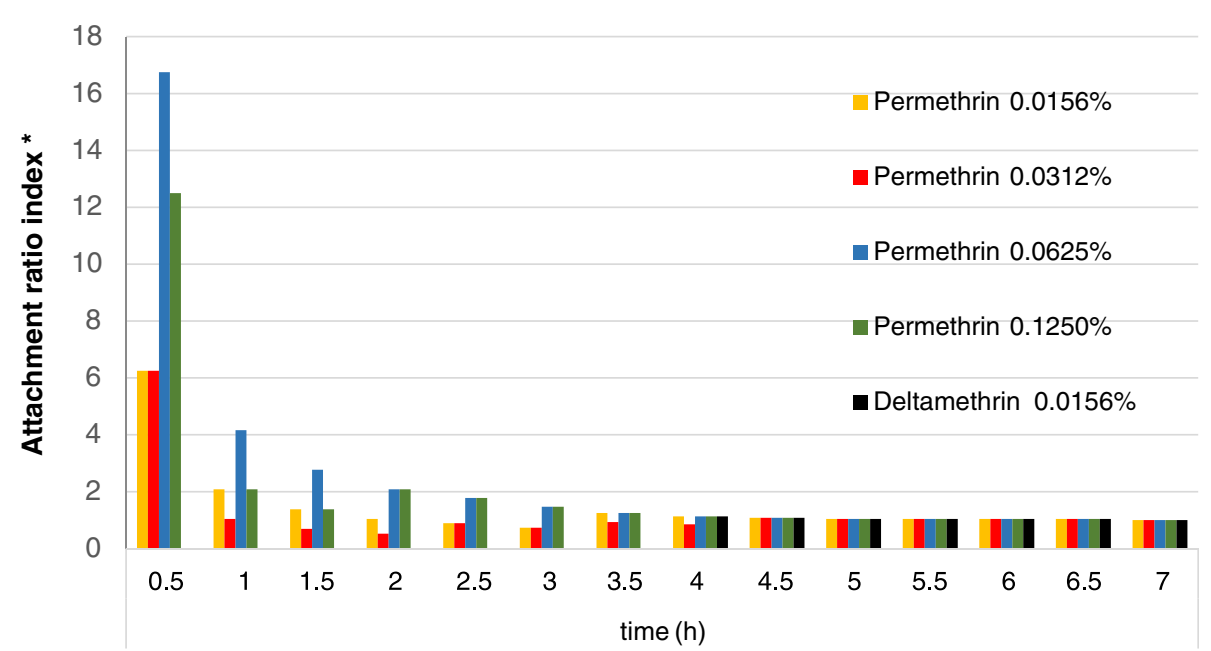

Fig. 1 Attachment ratio index ${ }^{*}$ of Dermacentor reticulatus females under the influence of pyrethroids studied; the study was performed at

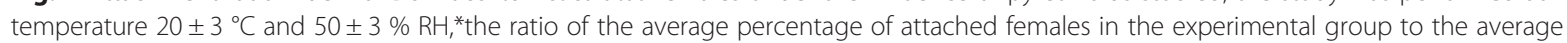
percentage of attached females in the control group at a specific time of the experiment 


\section{Competing interests}

The authors declare that they have no competing interests.

\section{Authors' contributions}

$A B$ formulated the idea and drafted the manuscript; PL-K performed laboratory procedures as well as statistical analysis; KB participated in the data analysis and in writing of the manuscript, provided critical comments to the methods and the discussion. All authors have approved the final version of this manuscript.

\section{Acknowledgments}

We are grateful to Anna Zon for the language editing of the manuscript.

Received: 17 June 2015 Accepted: 1 July 2015

Published online: 11 July 2015

\section{References}

1. Bartosik K, Sitarz M, Szymańska J, Buczek A. Tick bites on humans in the agricultural and recreational areas in south-eastern Poland. Ann Agric Environ Med. 2011;18:151-7.

2. Galbiati Terçariol PR, Godinho AF. Behavioral effects of acute exposure to the insecticide fipronil. Pest Biochem Physiol. 2011;99:221-5.

3. Kumar S, Lata S, Gopal K. Deltamethrin induced physiological changes in freshwater cat fish Heteropneustes fossilis. Bull Environ Contam Toxicol. 1999;62:254-8

4. Yang PY, Lin JL, Hall AH, Tsao TCY, Chem MS. Acute Ingestion Poisoning with Insecticide Formulations Containing the Pyrethroid permethrin, Xylene, and Surfactant: a review of 48 cases. Clin Toxicol. 2002;40:107-13.

5. Bianchi MW, Barré N, Messad S. Factors related to cattle level resistance to acaricides in Boophilus microplus tick populations in New Caledonia. Vet Parasitol. 2003;112:75-89.

6. Chareonviriyaphap T, Bangs MJ, Suwonkerd W, Kongmee M, Corbel V, Ngoen-Klan R. Review of insecticide resistance and behavioral avoidance of vectors of human diseases in Thailand. Parasit Vectors. 2013;6:280.

7. Schreck CE, Snoddy EL, Mount GA. Permethrin and repellents as clothing impregnants of protection from lone star tick. J Econ Entomol. 1980;73:436-9.

8. Faulde M, Scharninghausen J, Tisch M. Preventive effect of permethrinimpregnated clothing to Ixodes ricinus ticks and associated Borrelia burgdorferi s.l. Inter J Med Microbiol. 2008;51:321-4.

9. Lane RS. Treatment of clothing with a permethrin spray for personal against western black-legged tick Ixodes pacificus (Acari: Ixodidae). Exp Appl Acarol. 1989;6:343-52.

10. Horak IG, Fourie JJ, Stanneck D. Efficacy of slow-release collar formulations of imidacloprid/flumethrin and deltamethrin and of spot-on formulations of fipronil/(s) - methoprene, dinotefuran/pyriproxyfen/permethrin and (s) -methoprene/amitraz/fipronil against Rhipicephalus sanguineus and Ctenocephalides felis felis on dogs. Parasit Vectors. 2012;5:79.

11. Stanneck D, Kruedewagen EM, Fourie JJ, Horak IG, Davis W, Krieger KJ. Efficacy of an imidacloprid/flumethrin collar against fleas, ticks, mites and lice on dogs. Parasit Vectors. 2012;5:102.

12. Brianti E, Falsone L, Napoli E, Prudente C, Gaglio G, Giannetto S. Efficacy of a combination of $10 \%$ imidacloprid and $4.5 \%$ flumethrin (Seresto ${ }^{\oplus}$ ) in slow release collars to control ticks and fleas in highly infested dog communities. Parasit Vectors. 2013;6:210.

13. Mehlhorn H, Schumacher B, Jatzlau A, Abdel-Ghaffar F, Al Rasheid KA, Klimpel S, et al. Efficacy of deltamethrin (Butox 7.5 pour on) against nymphs and adults of ticks (Ixodes ricinus, Rhipicephalus sanguineus) in treated hair of cattle and sheep. Parasitol Res. 2011;108:963-71.

14. Lüssenhop J, Bäumer W, Kietzmann M, Schnieder T, Wolken S. Dynamics of distribution and efficacy of different spot-on permethrin formulations in dogs artificially infested with Dermacentor reticulatus. Parasit Vectors. 2011;4:45.

15. Buczek A, Bartosik K, Kuczyński P. Evaluation of the effect of various concentrations of selected pyrethroids on the development of Dermacentor reticulatus eggs and larvae. Ann Agric Environ Med. 2013;20:447-51.

16. Buczek A, Bartosik K, Kuczyński P. Sensitivity to permethrin in a Dermacentor reticulatus population from eastern Poland in laboratory study. Parasit Vectors. 2014;7:18.

17. Buczek A, Bartosik K, Kuczyński P. Comparison of the toxic effect of pyrethroids on Ixodes ricinus and Dermacentor reticulatus females. Ann Agric Environ Med. 2014;21:263-6.
18. Buczek A, Bartosik K, Kuczyński P. The toxic effect of permethrin and cypermethrin on engorged Ixodes ricinus females. Ann Agric Environ Med. 2014;21:259-62.

19. Mohamed FS, Abbassy MM, Darwish ZE, Tetreault GE, Marzouk AS, Shoukry MA, et al. Effects of permethrin on the salivary glands and neuroendocrine organs of unfed female Hyalomma (Hyalomma) dromedarii (Ixodoidea: Ixodidae). J Med Entomol. 2000;37:393-400.

20. Roma GC, Vendramini CR, Camargo-Mathias MI, Nunes PH, Uemura de Faria A, Bechara GH. Action of andiroba oil and permethrin on the central nervous and reproductive systems of Rhipicephalus sanguineus (Latreille, 1806)(Acari: Ixodidae) ticks females. A confocal study. Res Vet Sci. 2013;95:529-36.

21. Roma GC, Camargo-Mathias MI, Oliveira PR, Furquim KCS, Bechara GH. Neurotoxic action of permethrin in Rhipicephalus sanguineus (Latreille, 1806)(Acari: Ixodidae) female ticks. Morphological and cytochemical evaluation of the central nervous system. Vet Parasitol. 2013;196:482-91.

22. Šimo L, Zitňan D, Park Y. Neural control of salivary glands in ixodid ticks. J Insect Physiol. 2012;58:459-66.

23. Roma GC, Furquim KCS, Bechara GH, Camargo-Mathias MI. Permethrininduced morphological changes in oocytes of Rhipicephalus sanguineus (Acari: Ixodidae) semi-engorged females. Food Chem Toxicol. 2010;48:825-30.

24. Nodari EF, Roma GC, Scopinho Furquim KC, Bechara GH, Carmago Mathias MI. Cytotoxic effects of permethrin in salivary glands of Rhipicephalus sanguineus (Latreille, 1806)(Acari: Ixodidae) semi-engorged females. Exp Parasitol. 2011;128:151-8.

25. Pereira CP, Oliveira PR, Furquim KC, Bechara GH, Camargo-Mathias MI. Fipronil-induced cell death in salivary glands of Rhipicephalus sanguineus (Latreille, 1806)(Acari: Ixodidae) semi-engorged females. Exp Parasitol. 2011;127:481-9.

\section{Submit your next manuscript to BioMed Central and take full advantage of:}

- Convenient online submission

- Thorough peer review

- No space constraints or color figure charges

- Immediate publication on acceptance

- Inclusion in PubMed, CAS, Scopus and Google Scholar

- Research which is freely available for redistribution 